Original article

\title{
Evaluation of the relationship between compliance with professional ethics and job satisfaction among nurses
}

\author{
Zahra Fallahnejad', Ramazan Hassanzadeh', Hamideh Azimi lolaty ${ }^{2, *}$
}

(Received: 5 Nov 2014; Accepted: 31 May 2015)

\begin{abstract}
Background and Purpose: Professional ethics is one of the foremost components of every occupation. The ethical standards are essential to the improvement of quality of care. On the other hand, job satisfaction is a critical challenge for healthcare organizations. This study aimed to evaluate the relationship between compliance with professional ethics and job satisfaction among nurses.

Methods: This descriptive-correlational study was conducted on 142 nurses employed in the teaching hospitals of Sari, Iran. Participants were selected via stratified random sampling. Data collection tools were Cadozier's professional ethics questionnaire (2002), and Warr, Cook, and Wall's job satisfaction scale (1979). Data analysis was performed in SPSS V.14 using t-tests, Pearson's correlationcoefficient, and one- way Analysis of Variance (ANOVA).

Results: In this study, the majority of the participants were female (90.1\%), registered nurses (81.7\%), and had bachelor's degree (92.3\%). Mean scores of compliance with professional ethics and job satisfaction were $62.01 \pm 6.92$ and 47.86 \pm 9.94 , respectively. No significant correlation was observed between compliance with the professional ethics and job satisfaction $(\mathrm{P}=0.113)$. Moreover, there was a significant association between the observance of professional ethics and work experience of the nurses $(\mathrm{P}=0.032)$. Accordingly, nurses with more than 10 years of work experience had greater compliance with professional ethics.

Conclusion: According to the results of this study, compliance with professional ethics and job satisfaction are independent from each other. This may be due to the fact that in nursing professional ethics has a intrinsic and independent feature in compared to other parameters, such as payment equity, job bonus, and promotion, which could increase or reduce job satisfaction among these healthcare providers.
\end{abstract}

Keywords: Job satisfaction, Nurse, Professional ethics

\section{Introduction}

Nursing profession essentially involves respecting human rights in different aspects, such as the cultural beliefs and integrity of individuals (1). Professional ethics is the indispensible element of nursing, which grants meaning and direction to the personal life of nurses (2). Ethical background of individuals determines their general tendencies in life and affects one's critical decision-making (3). Nursing ethics is a branch of medical ethics, which has been influenced by the developments in this field (4).

According to the definition proposed by the American Nurses Association, nursing performance must be based on the standards of professional ethics in providing clinical care and decision-making (5). In this regard, Gallagher and Tschudin (2010) have stated that nursing staff are the ethical leaders of every healthcare system, and it is of paramount

\footnotetext{
${ }^{1}$ Department of Psychology, Sari Islamic Azad University, Sari, Iran

2,* Corresponding author: Department of Psychiatric Nursing, Psychiatric and Behavioral Sciences Research Center, Mazandaran University of Medical Sciences, Sari, Iran. Email: azimihamideh@gmail.com
} 
importance to protect the ethical identity of these professionals. Assuming diverse ethical leadership levels, they considered every nurse as an independent ethical leader in healthcare organizations. As such, nursing managers are required to encourage and motivate nursing teams to enhance their leadership abilities (6).

In two other studies, McKinstry and Bailey claimed that in many cases, ethical considerations are neglected by nursing staff in the provision of care, and this undermines the independence of patients (7). In the research conducted by Tamizi et al. (2005) in the psychiatric wards of different hospitals in Tehran (Iran), optimal observance of patient rights was reported in only $25 \%$ of nurses. Similarly, Dinmohammadi (2003) reported that $86.7 \%$ of nursing staff had poor communication with patients, and $49.6 \%$ neglected patient rights during medication therapy (8).

Nurses are faced with ethical challenges on a daily basis and may frequently experience ethical distress in critical decision-making (7). Permanent ethical distress leads to low quality of life, reduced job satisfaction, job burnout, work aversion, decreased job survival, change of position, and turnover. Moreover, ethical distress adversely affects the performance of nurses, leading to poor interactions with patients and their relatives, staff shortage, and reduced quality of care (9). Nurses to deal with the underlying moral distress, nurses need to adopt effective strategies; for instance, trying to influence on the behavior of leaders and decision-makers, reporting errors, and actively discuss issues with the related officials and physicians (3).

The concept of job satisfaction has been frequently addressed in various healthcare organizations since 1920s (10). Job satisfaction is a multidimensional structure defined variably by different theoreticians. In the literature, nursing researchers have defined job satisfaction as the positive attitude towards nursing profession (11). Job satisfaction, especially among nurses, is considered as a significant challenge in healthcare organizations (10). Previous studies have reported various findings with regard to the level of job satisfaction in different countries (12). Accordingly, the highest rate of job satisfaction has been reported in the United States (41\%), Scotland (38\%), England (36\%), Canada (33\%), and Germany (17\%), respectively (10).

In Iran, several studies have evaluated the level of job satisfaction among nurses. For instance, in the study by Mogharrab et al., only 3.2\% of the nurses were reported to have high job satisfaction (13). In addition, the results obtained by Afshari Moghaddam and Golchin indicated that $63 \%$ of nurses were dissatisfied with their job. Job dissatisfaction among nurses creates a vicious circle leading to increased turnover rate and nursing staff shortage. These factors lead to higher job dissatisfaction, as well as the exhaustion caused by heavy workload and prolonged work shifts. In the long run, negligence of job satisfaction interrupts the proper function of healthcare organizations, reduces the sense of responsibility, and increases turnover rates (14).

Considering the challenges associated with nursing during education and recruitment, numerous factors are known to affect the level of job satisfaction in these healthcare professionals; such examples are prolonged work shifts, mandatory overtime hours, and ambiguity in job description. On the other hand, job satisfaction of nurses could be enhanced through the adjustment of work shifts, job bonus, and payment equity (11).

Compliance with the standards of professional ethics will bring about job satisfaction, as well as positive psychological responses, such as the sense of contentment and higher motivation, in nurses (15). To date, no studies have investigated the relationship between the observance of professional ethics and level of job satisfaction in nurses. This study aimed to evaluate the association between compliance with professional ethics and job satisfaction among nurses.

\section{Materials and Methods}

This descriptive-correlational study was conducted on 142 nurses employed in the teaching hospitals of Sari in Mazandaran province, Iran.

In order to select the participants, a complete list of the nurses working in the teaching hospitals of Sari was obtained from the nursing office of these 
institutions. After encoding, 142 nurses were selected via stratified random sampling. Participants were divided into two groups of male and female nurses. Community ratio of the study groups was determined at 0.1 and 0.9 for male and female participants, respectively using the following formula:

$$
P=(n / N)
$$

In addition, ratio of each group to the study community was calculated based on the following formula (16):

$$
n k=p . n
$$

Ultimately, the number of samples in each study group was estimated at 14 male and 128 female nurses (total number: 142), who were randomly selected by drawing lots.

Data collection tools included demographic questionnaire, Cadozier's professional ethics questionnaire (2002), and Warr, Cook, and Wall's job satisfaction scale (1979).

Cadozier'sprofessional ethics questionnaire consists of 16 items to measure the observance of professional ethics in eight domains, including responsibility (two items), sincerity and honesty (two items), fairness and justice (two items), dominance and racing (two items), respect (two items), sympathy (two items), respecting social values (two items), and loyalty (two items).

To complete this questionnaire, participants were asked to choose the option that was closest to their personal views, as follows: very high (score 5), high (score 4), moderate (score 3), low (score 2), and very low (score 1). Level of compliance with professional ethics standards was determined based on the total score achieved by the participants. Minimum and maximum scores in Cadozier's professional ethics questionnaire were 16 and 80, respectively, and higher scores denoted the higher compliance of the participants with professional ethical codes.

Validity of Cadozier's professional ethics questionnaire for the Iranian population has been confirmed in the study by Mohajeran and Shohoudi (17). In addition, reliability of this questionnaire was determined using the test retest method. To do so, we randomly selected 10 nurses who completed the questionnaire at a two-week interval, and the reliability was estimated at 0.86 . In the study by Mohajeran and Shohoudi, reliability coefficient of Cadozier's professional ethics questionnaire was reported to be 0.79 (17).

In this study, job satisfaction of nurses was evaluated using the Warr, Cook, and Wall's (1979) job satisfaction scale consisting of 15 items, which were graded by the participants, as follows: very satisfied (score 5), satisfied (score 4), indifferent (score 3), dissatisfied (score 2), and very dissatisfied (score 1). Minimum and maximum scores of this questionnaire were 15 and 75 , respectively.

In their research, Asghari et al. confirmed the validity of the Warr, Cook, and Wall's job satisfaction scale, and reliability coefficient of this scale has been reported to be 0.97 (18). Moreover, the reliability of this scale was estimated at 0.78 using the retest method in the present study.

The questionnaires were distributed among the ward managers of morning hospital shifts to be completed by the nursing staff. With adequate time and frequent follow-ups, 142 questionnaires were completed and collected. With regard to ethical considerations, the questionnaires were only used for research purposes, and personal information of the participants remained confidential.

Data analysis was performed in SPSS V.14 using descriptive and inferential statistics, and Pvalue of 0.05 was considered significant. After test of normality of data $(\mathrm{P}=0.25)$ to determine the relationship between professional ethics and job satisfaction, Pearson's correlation-coefficient was used. In addition, we used independent $t$-test to compare the association between compliance with professional ethics and job satisfaction among male and female nurses. Also, one-way analysis of variance (ANOVA) was used to evaluate the compliance with professional ethics and also job satisfaction in terms of the work experience and education level of the participants.

\section{Results}

Out of 142 nurses enrolled in this study, 14 were 
Table 1. Distribution of nurses in terms of demographic characteristics (2014)

\begin{tabular}{lccc}
\hline Variables & & $\mathbf{N}$ & $\mathbf{\%}$ \\
\hline \multirow{2}{*}{ Demographic } & $20-30$ & 57 & 40.1 \\
Characteristics & $30-40$ & 61 & 43 \\
Age (years) & $40-50$ & 23 & 16.2 \\
& $50-60$ & 1 & 0.7 \\
\hline \multirow{2}{*}{ Gender } & Male & 14 & 9.9 \\
& Female & 128 & 90.1 \\
\hline \multirow{2}{*}{ Work Experience } & $<10$ & 102 & 71.8 \\
(years) & $10-20$ & 32 & 22.5 \\
& $20-30$ & 8 & 5.6 \\
\hline \multirow{2}{*}{ Education Level } & Associate Degree & 4 & 2.892 .3 \\
& Bachelor's Degree & 131 & 4.9 \\
\hline
\end{tabular}

male $(9.9 \%)$, and 128 were female $(90.1 \%)$, and 61 participants $(43 \%)$ were within the age range of $30-40$ years. In this study, 102 nurses $(71.8 \%)$ had less than 10 years of work experience, $32(22.5 \%)$ had 11-20 years of work experience, and 8 nurses (5.6\%) had 21-30 years of experience. With regard to education level, four participants had associate degree (2.8\%), 131 (92.3\%) had bachelor's degree, and seven nurses had master's degree (4.9\%).

The results of Pearson's correlation-coefficient were indicative of no significant correlation between compliance with professional ethical and job satisfaction in the subjects $(\mathrm{P}=0.113)$. Moreover, mean score of professional ethics observance was higher in female nurses compared to male nurses; however, the difference was not statistically significant $(\mathrm{P}=0.878)$. Consequently, no significant difference was observed between male and female patients in terms of the observance of professional ethics (Table 2).

According to the results of ANOVA, observance of professional ethics had a significant correlation with the work experience of nurses $(\mathrm{P}=0.032)$. In other words, level of compliance with professional ethics was lower among nurses with less than 10 years of experience compared to those with work experience

Table 3. Correlations between professional ethics observance, work experience, and education level of nurses (2014)

\begin{tabular}{|c|c|c|c|c|c|}
\hline $\begin{array}{l}\text { Resources/ } \\
\text { Variables }\end{array}$ & SS & Df & MS & F & $\mathbf{P}$ \\
\hline $\begin{array}{l}\text { Work Experience } \\
\text { Inter-groups } \\
\text { Intra-groups } \\
\text { Total }\end{array}$ & $\begin{array}{c}327.42 \\
6432.54 \\
6759.6\end{array}$ & $\begin{array}{c}2 \\
139 \\
141\end{array}$ & $\begin{array}{c}163.714 \\
46.277\end{array}$ & 3.538 & 0.033 \\
\hline $\begin{array}{l}\text { Education Level } \\
\text { Inter-groups } \\
\text { Intra-groups } \\
\text { Total }\end{array}$ & $\begin{array}{c}58.41 \\
6701.55 \\
6759.97\end{array}$ & $\begin{array}{c}2 \\
139 \\
141\end{array}$ & $\begin{array}{l}29.206 \\
48.213\end{array}$ & 0.606 & 0.547 \\
\hline
\end{tabular}

Table 2. Comparison of mean scores of professional ethics observance in terms of gender (2014)

\begin{tabular}{|c|c|c|c|c|c|c|}
\hline $\begin{array}{l}\text { Statistical } \\
\text { Indices/ } \\
\text { Variables }\end{array}$ & $\mathbf{N}$ & Mean & $\begin{array}{l}\text { Standard } \\
\text { Deviation }\end{array}$ & t & Df & P-value \\
\hline $\begin{array}{l}\text { Observance of } \\
\text { Professional } \\
\text { Ethics in Male } \\
\text { Nurses }\end{array}$ & 14 & 62.28 & 8.50727 & \multirow{2}{*}{0.154} & \multirow{2}{*}{140} & \multirow{2}{*}{0.878} \\
\hline $\begin{array}{l}\text { Observance of } \\
\text { Professional } \\
\text { Ethics in Female } \\
\text { Nurses }\end{array}$ & 128 & 61.98 & 6.76837 & & & \\
\hline
\end{tabular}

of 11-30 years (Table 3). Additionally, the results of ANOVA indicated that the level of compliance with professional ethics was significantly different in terms of the education level of the nurses $(\mathrm{P}=0.547)$ (Table 3$)$.

\section{Discussion}

The findings of the present study were indicative of no significant correlation between compliance with professional ethics and job satisfaction in nurses. In one study, Joulaee et al. reported a significant relationship between the moral atmosphere of workplace and level of job satisfaction among the nurses employed in the teaching hospitals of Tehran, Iran. According to their findings, favorable ethical environment is associated with higher job satisfaction of the nursing staff (19).

In another research, Joseph \& Deshpande (2006) claimed that ethical work environment could have remarkable effects on different aspects of job satisfaction (20). Similarly, the findings of Mcclendon and Buchner (2007), Rushton (2006), and Hamric, Davis \& Childress (2006) indicated that moral distress in nurses would lead to problems such as discouragement and poor job satisfaction (21-23). The present study revealed that compliance with professional ethics plays a less significant role in improving the job satisfaction of nurses in comparison with other parameters, such as job bonus, payment equity, and promotions. It may be due to intrinsic and independent feature of professional ethics in body of nursing profession.

In the current research, no significant correlation was found between the observance of professional ethics and gender of the nurses. This is in line with the findings of Beik-Moradi et al., Hassanpour et al., Vaziri et al., and Alpern et al. $(9,15,24,25)$. 
However, this finding is inconsistent with the results obtained by Dehghani and Mohammad Khan Kermanshahi, which indicated that female nurses ethically outperformed in compare with male nurses (1). In the present study, no significant difference was observed between the ethical performance of male and female nurses, which could be due to the limited number of male nurses in the study population $(\mathrm{n}=14)$.

According to the results of the current research, nurses with less than 10 years of work experience had lower compliance with professional ethics compared to those with work experience of 11-30 years. This is in line with the results obtained by Dehghani, Mohammad Khan Kermanshahi and Alpern et al. $(1,25)$. However, it is inconsistent with the findings of Karampourian et al., Beik-Moradi et al., Vaziri et al., and Hassanpour et al. (9, 15, 24, 26). This could be due to the exclusion of nursing ethics education courses from the curriculum of nursing students. As such, nurses are not adequately trained on the pivotal role of professional ethics in the effective provision of clinical care.

In some cases, although nurses may feel the need to adopt appropriate ethical strategies in a clinical situation, they might fail to adhere to professional ethical standards due to different barriers, such as lack of time and interference of authorities. Consequently, nurses may experience moral distress, which leads to the reduction of ethical sensitivity and observance (9). On the other hand, increased work experience is associated with a more realistic attitude towards clinical issues, as well as the development of clinical skills, which heightens the sensitivity of nurses for compliance with professional ethical standards (22).

\section{Conclusion}

According to the results of the present study, level of professional ethical observance was lower among nurses with less than 10 years of work experience. Domestic and foreign studies in this regard have suggested various challenges against the ethical commitment of nurses, including unfavorable feedback from nursing managers, stressful work environment, inefficient communication of nurses (with patients, physicians and colleagues), changeable attitude of physicians towards the nursing staff, overlooking the competency of nurses, and lack of support by nursing authorities. Furthermore, inadequate education on the importance of nursing ethics is considered as a major influential factor in the low observance of professional ethics among nurses. Therefore, it is recommended that nursing authorities regularly evaluate nursing work environment in order to identify the underlying factors affecting ethical considerations. Moreover, it is of paramount importance to include ethical education courses in the curriculum of nursing students and offer related training workshops in hospitals.

\section{Conflicts of interest}

None declared.

\section{Author's contributions}

Z Fallahnejad collected and analyzed the data and prepared the draft of the paper. R Hassanzadeh evaluated the process of study. H Azimi lolaty and evaluated and supervised the entire process of analysis and publish of the paper.

\section{Acknowledgements}

Hereby, we extend our gratitude to the nursing office, supervisors and all the nurses of Bu-AliSina Hospital of Sari for assisting us in this research project.

\section{References}

1. DehghaniA, Mohammadkhan KS. Evaluating of compliance with professional ethical standards in nursing practice from nursing staff's viewpoints in Tehran university of medical sciences. Modern Care J 2012; 9(3):208-16 (Persian).

2. Mahmoodi Shan G, Alhani F, Kazemnejad A. Ethics in nurses' lifestyle: a qualitative study. Iran J Med Ethics History Med 2009; 2(4):63-78 (Persian).

3. Shakeriniya I. Moral distress: the latent stress in nursing. 
Iran J Med Ethics History Med 2011; 4(3):26-35 (Persian).

4. Borhani F, Alhani F, Mohammadi I, Abbaszadeh A. professional nursing ethics: it's development and challenges. Iran J Med Ethics History Med 2009; 2(3):27-38 (Persian).

5. Moarefi F, Ashktorab T, Abbaszadeh A, Alavimajd H. Investigating the viewpoints of patients regarding the compliance of codes of professional ethics by nurses at Jahrom hospitals of medical sciences. Iran J Bioet 2013; 3(10):35-57.

6. Gallagher A, Tschudin V. Educating for ethical leadership. Nurse Educ Today 2010; 30(3):224-7.

7. Habibzade H, Ahmadi F, Vanaki Z. Ethics in professional nursing in Iran. Iran J Med Ethics History Med 2010; 3(5):27-36 (Persian).

8. Sadeghi R, Ashk Torab T. Ethical problems observed nursing students: qualification approach. Med Ethics 2011; 5(15):43-62 (Persian).

9. Beikmoradi A, Rabiee S, Khatiban M, Cheraghi MA. Nurses distress in intensive care unit: a survey in teaching hospitals. Iran J Med Ethics History Med 2012; 5(2):53-63 (PersainPersian).

10. Bagheri S, Koosha A, Janati A. Factors affecting nurses' job satisfaction: a systematic survey. Hakim Med J 2012; 15(2):130-9 (Persian).

11. Mirzabeigi GH, Salemi SE, Sanjari MA, Shirazi FA, Heidari SH, Maleki SE. Job satisfaction among nurses. Hayat 2008; 1(15):49-59 (PersainPersian).

12. Kreitner R, Kinicki A. Organizational behavior. Trans: Farangy H, Safarzade B. Theran: Pyam Poya Press; 2007 (Persian).

13. Mogharrab M, Madarshahian F, Aliabadi N, Rezaee N, Mohamadi AB. Investigating job satisfaction among nurses in teaching hospitals of Birjand in 2004. J Birjand Univ Med Sci 2005; 12(3-4):92-9 (PersainPersian).

14. Abbaschian R, Avazeh A, Rabi Siahkalis S. Job satisfaction and its related factors among nurses in the public hospitals of Zanjan university of medical sciences, 2010. Prev Care Nurs Midwifery J 2011; 1(1):17-24.

15. Hasanpour M, Hosseini M, Fallahi Khoshknab M,
Abbaszadeh A. Evaluation of the impact of teaching nursing ethics on nurses' decision making in Kerman social welfare hospitals in 2010. Iran J Med Ethics History Med 2011; 4(5):58-64 (PersainPersian).

16. Hasanzadeh R. Motivation and emotion. Tehran: Arasbaran Press; 2011 (PersainPersian).

17. Mohajeran B. Structural modeling of relationship between professional ethics and spirituality at work with social responsibility among nurses in the public hospitals of Kermanshah city. Q J Nurs Manag 2014; 3(2):20-9.

18. Asghari E, Khaleghdoust T, Asgari F, Kazemnejad E. Effective factors on nurses' job satisfaction. Holistic Nurs Midwiferi 2010; 20(64):1-7 (PersainPersian).

19. Joolaee S, Jalili HR, Rafiee F, Hajibabaee F, Haghani H. The relationship between ethical climate at work and job satisfaction among nurses in Tehran. Indian J Med Ethics 2013; 10(4):238-42.

20. Joseph J, Deshpande SP. The impact of ethical climate on job satisfaction of nurses. Health Care Manag Rev 2006; 22(1):207-16

21. Mclendon H, Buckner EB. Distressing situations in the intensive care unit: a descriptive study of nurses responses. Dimens Crit Care Nurs 2007; 26(5):199-206.

22. Rushton $\mathrm{CH}$. Defining and addressing moral distress: tools for critical care nursing leaders. AACN Adv Crit Care 2006; 17(2):161-8.

23. Hamric AB, Davis WS, Chidress MD. Moral distress in health care professionals. Pharos Alpha Omega Alpha Honor Med Soc 2006; 69(1):16-23.

24. Vaziri M, Emami M, Salsali M, Gushegir J. Developing the moral distress scale in the population of Iranian nurses. Teb va Tazkieh 2008; 3(4):46-55 (Persian).

25. Elpern EH, Covert B, Kleinpell R. Moral distress of staff nurses in a medical intensive care unit. Am J Crit Care 2005; 14(6):523-30.

26. Karamporian A, Imeni B, Torkzaban P. The attitude of faculty members towards professional ethics at Hamadan university school of dentistry. J Res Dental Sci 2013; 10(1):43-51 (Persian). 